\title{
Uncertainty as a moderator of the relationship between job satisfaction and occupational stress
}

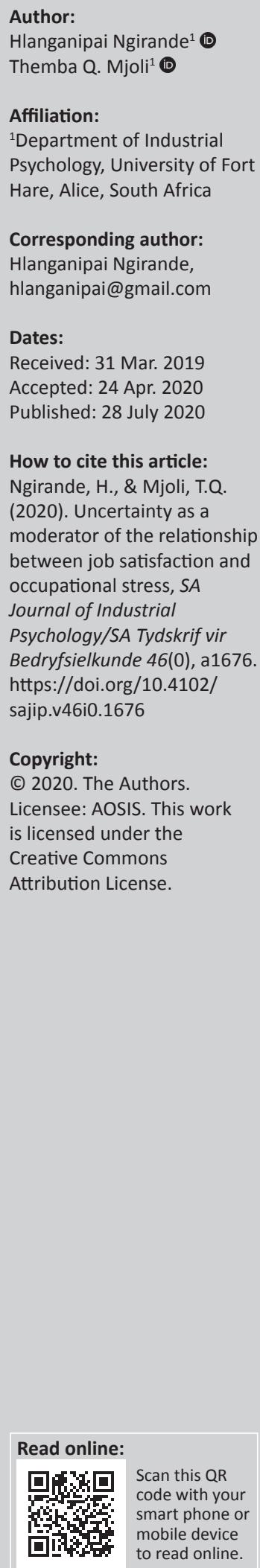

Orientation: Organisations need to manage the behaviours and attitudes of their workforce to remain competitive, effective and efficient. Therefore, it is important to understand job dissatisfaction and stress levels to minimise their negative effect on both individuals and the organisation as a whole.

Research purpose: The study sought to compare the levels of job satisfaction and occupational stress of employees in merged and non-merged higher learning institutions and investigated the moderating role of uncertainty in the relationship between job satisfaction and occupational stress.

Motivation for the study: The study aimed to contribute a new model to explain the role of uncertainty in job satisfaction and occupational stress.

Research approach/design and method: The study used a quantitative survey research technique. A total sample of 424 respondents completed a self-administered questionnaire.

Main findings: Employees in both merged and non-merged institutions were satisfied but showed differed levels of occupational stress. No relationship was found between job satisfaction or uncertainty and occupational stress. Furthermore, uncertainty significantly moderated the relationship between job satisfaction and occupational stress.

Practical/managerial implications: Human resource managers should reduce the uncertainty of employees to increase job satisfaction and reduce the negative effects of occupational stress.

Contribution/value-add: Recommendations from the study could assist management to monitor the behaviours and attitudes of employees during and after organisational change. The study also contributed to the body of knowledge as no single study of this nature has been carried out in South African higher learning institutions.

Keywords: Job insecurity; higher education institutions; satisfaction; stress; academics; uncertainty.

\section{Introduction and background}

Mergers are extreme forms of organisational change, often seen as stressful by employees. Employees become concerned about their organisational structure, to whom they are going to report, how communication patterns will change and how restructuring will affect their salaries and benefits (Cartwright \& Cooper, 2014). Mergers are therefore stressful life events even when the cultures of the merging organisations are similar (Barkhuizen \& Rothmann, 2008).

While mergers are often carried out to improve the organisation's functioning and profitability, they can also have an unintended negative impact on employee attitudes. Zagelmeyer, Sinkovics, Sinkovics and Kusstatscher (2018) report that mergers result in low job satisfaction among employees who see their job security threatened. This may result in stress. Moreover, Coffey, Garrow and Holbeche (2012) argue that lack of communication, unfair and unclear implementation processes often lead to uncertainty during a merger. These uncertainties could lead to low job satisfaction and high occupational stress (Cooper, 2018). Mergers must, therefore, be carried out in such a way that employee job satisfaction is not affected, and that occupational stress is minimised (Martin \& Roodt, 2008).

Stress can be viewed as an individual's response to the self-perceived imbalance between the demands of the present situation and available resources (Boyd, Tuckey, \& Winefield, 2014). Organisational change such as a merger can lead to high uncertainty, and this can stimulate occupational stress. These uncertainties are, however, often more stressful to employees than the 
actual changes themselves (Martin \& Roodt, 2008). This study argues that it is not only the merger that may lead to job dissatisfaction and high occupational stress, but it is also the uncertainty of retaining one's job following the merger.

The South African higher education sector is also affected by mergers. These mergers bring challenges such as high levels of uncertainty about job security, high levels of occupational stress and low job satisfaction among employees in South African institutions of higher learning. According to Section 23 of the Higher Education Act (Act No. 101 of 1997), a merger occurs when two or more separate organisations join to become a single entity with one governing body. Research shows that if the merger is not done properly, it can have a negative effects on employees' job satisfaction and occupational stress (Burke, 2017). These negative effects may be influenced by uncertainties about future job security. In this study, a comparison of the employees' level of job satisfaction and occupational stress in merged and non-merged higher learning institutions will be done.

\section{Job satisfaction}

Job satisfaction can be viewed as a pleasurable or positive feeling resulting from the assessment of one's job or job experiences (Cooper, 2018). According to Burke (2017), employees who are less satisfied with their organisation are highly stressed.

Authorities in higher education institutions should, therefore, understand the factors affecting the workforce's satisfaction. Higher learning institutions should also understand the impact job satisfaction has on employees' levels of occupational stress, particularly when changes like a merger take place. A study by Van der Westhuizen (2001) revealed that educators become dissatisfied when new educational policies are being introduced and new structures emerge as a result of interventions such as mergers.

Various factors influence employee job satisfaction. These include pay, working conditions, relationships with colleagues and supervisor support. Therefore, for institutions to remain productive and efficient, they should make sure that their employees are satisfied with their working environments.

\section{Occupational stress and uncertainty}

Boyd et al. (2014) define stress as the individual's response to an imbalance that is perceived between the demands made in the situation and the resources available. Organisational change such as a merger can lead to high uncertainty, which can stimulate occupational stress. These uncertainties are, however, often more stressful to employees than the actual changes themselves (Cooper, 2018). According to Slade, Ribando and Fortner (2016), mergers lead to stress among employees who feel that their job security is being threatened.
This study argues that it is not only the merger that may lead to job dissatisfaction and high occupational stress, but it is also the uncertainty of retaining one's job following the merger.

The demands made on an individual, known as stressors, serve as a stimulus for evoking a response, such as emotions of anger, anxiety, and stress (Cooper, 2018). These stressors can be internal or external. Although a single stressor may cause major stress, stressors usually combine to put pressure on an employee in a variety of ways until stress develops (Graebner, Heimeriks, Huy, \& Vaara, 2017). Hence, one can argue that organisations should take note of these stressors to minimise employee occupational stress and improve job satisfaction.

A merger may cause employees to experience stress when they become anxious about possible events such as downsizing, layoffs and increasing workloads (Graebner et al., 2017). This could be because mergers are often associated with reduced morale and job dissatisfaction rather than with increased financial performance as expected (Graebner et al., 2017). Moran and Panasian (2005) also point out that mergers are a major source of stress due to uncertainties about organisational changes. However, these uncertainties are often more stressful to employees than the actual changes themselves (Cooper, 2018).

Uncertainty has not received as much attention in the occupational stress literature as other psychosocial stressors.

Studies have shown that employees who perceive that they have an uncertain future in their jobs often feel threatened and anxious and may exhibit symptoms of distress such as depression (Bakker, Demerouti, \& Sanz-Vergel, 2014; Lee, Huang, \& Ashford, 2018). Therefore, organisations should minimise the uncertainties of job security especially during and after an organisational change. To minimise uncertainties in any organisation during and after a merger process, management should communicate the purpose and benefits of the organisational change (Bauer \& Matzler, 2014). This can be achieved if the merger process is done properly (Carleton \& Lineberry, 2004).

Mergers do not only affect employees' levels of uncertainty regarding their future job security, but they may also become uncertain about the future job demands, fringe benefits, as well as future organisational culture. All these uncertainties affect the behaviour and emotional well-being of employees in an organisation (Khan, Soundararajan, Wood, \& Ahammad, 2017). This study contends that it is this job dissatisfaction that leads to uncertainty and a higher level of occupational stress in a merged or merging institution than in a non-merging or non-merged institution. Therefore, the study investigates whether this is indeed the case.

\section{The relationship between job satisfaction, occupational stress and uncertainty}

Research shows that a negative relationship exists between job satisfaction and occupational stress (Burke, 2017; 
Khamisa, Oldenburg, Peltzer, \& Ilic, 2015; Yousef, 2002). This means that the more satisfied an individual is, the less the likelihood that the individual will experience occupational stress. However, Faragher, Cass and Cooper (2013) argue that there is no relationship between job satisfaction and occupational stress. Research on the relationship between uncertainty and occupational stress shows that there is a relationship between the two variables (Cooper, 2018; Vander Elst, Notelaers, \& Skogstad, 2018; Warr, 2011). However, most studies that have been done on the relationship between job satisfaction and occupational stress and uncertainty focused mainly on one institution. Little is known about these relationships from the perspective of two different institutions. In addition, there is a dearth of knowledge on whether the relationship between job satisfaction and occupational stress is moderated by uncertainty, hence the need to explore further.

Even though several studies have been conducted on the general effects of job satisfaction, very few of these studies explore whether job satisfaction influences employee occupational stress in tertiary institutions.

Furthermore, existing research sheds little light on the role of uncertainty as a moderator of this impact. In South Africa, most of the research on the impact of job satisfaction has revealed conflicting results. Some of the findings attribute low job satisfaction and high levels of occupational stress to mergers (Martin \& Roodt, 2008), while others relate mergers to high employee job satisfaction and low levels of occupational stress (Arnolds, Lillah, \& Stofile, 2013). Results on whether there are some differences in employee levels of job satisfaction and occupational stress between employees in merged and non-merged institutions have been largely inconclusive (Burke, 2017). This makes it necessary to explore the matter further. Thus, this study investigates and compares the extent of job satisfaction and occupational stress among employees in a merged or merging institution and employees in a non-merged institution.

\section{Research purpose}

The main purpose of this study was to compare the levels of employee job satisfaction and occupational stress in a merged and non-merged institution of higher learning in South Africa. The study also investigated whether uncertainty moderates the relationship between job satisfaction and occupational stress. This study is important as it determines the proportion of variance in satisfaction and occupational stress that is due to uncertainty and that which is due to the merger itself.

\section{Research objectives}

The objectives of the study are:

- To compare the levels of job satisfaction of employees in a merged and a non-merged institution.

- To compare the levels of occupational stress of employees in a merged and a non-merged institution.
- To investigate the relationship between job satisfaction and occupational stress.

- To investigate the relationship between uncertainty and occupational stress.

- To investigate the moderating role of uncertainty in the relationship between job satisfaction and occupational stress.

\section{Conceptual model}

A conceptual model was developed based on reviewed literature and the researchers' logical deductions. The conceptual model indicated the hypothesised relationship between job satisfaction and occupational stress, and the moderating role of uncertainty. The conceptual model is shown in Figure 1.

\section{Research hypotheses}

Reviewed literature reveals that there is a relationship between job satisfaction and occupational stress. It also shows that the relationship between job satisfaction and occupational stress may be influenced by the level of uncertainty among employees. Therefore, it is hypothesised that:

H1: Employees in merged institutions experience significantly lower levels of job satisfaction than those in a non-merged institution.

H2: Employees in merged institutions experience significantly higher levels of occupational stress than those in a non-merged institution.

H3: There is a relationship between employee job satisfaction and occupational stress.

H4: There is a relationship between uncertainty and occupational stress.

H5: Uncertainty moderates the relationship between job satisfaction and occupational stress.

\section{Research methodology}

\section{Research design}

The study used the quantitative approach, in particular the survey research technique, to collect data and test hypotheses. The approach was deemed appropriate since it is mainly used when a study aims to examine the relationships between variables and test research hypotheses (Creswell \& Creswell, 2017).

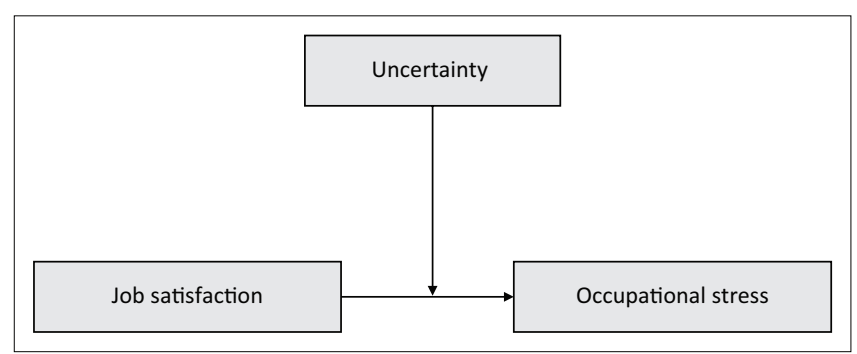

FIGURE 1: Uncertainty as a moderator of the relationship between job satisfaction and occupational stress. 


\section{Research participants}

A sample of 424 academic staff, 212 from a merged and 212 from a non-merged institution of higher learning, were selected using Raosoft sample size calculator online software. The overall sample had an equal number of male and female respondents. The highest number of participants, 194 (45.8\%), were aged between 36 and 45 years, followed by the $46-55$ years age group $160(37.7 \%)$. The lowest number of the participants were aged 25 years and below - $2(0.5 \%)$. Furthermore, the highest number of participants, 208 (49.1\%), were married, followed by singles 172 (40.6\%), and the widowed 20(4.7\%). Respondents were also asked to indicate their educational qualifications.

The majority had postgraduate degrees, 352 (83\%), with more than 10 years of working experience - 268 (63.2\%). See Table 1.

\section{Measuring instruments}

A self-administered questionnaire was used to collect data. The questionnaire consisted of job satisfaction, occupational stress and uncertainty scales. Job satisfaction was measured using the 10-item Halpern's (1966) job satisfaction questionnaire. The questionnaire measures satisfaction with various job content (motivator factors) and job context factors (hygiene factors), as well as overall job satisfaction. Examples of the items included in this scale are working conditions, opportunities for achievement, work itself and overall satisfaction.

To measure occupational stress, the 16-item Effort-Reward Imbalance questionnaire was used. The questionnaire previously established a coefficient alpha of $0.68-0.86$ from

TABLE 1: Sample profile.

\begin{tabular}{|c|c|c|c|}
\hline Variable & Category & Frequency & $\%$ \\
\hline \multirow[t]{2}{*}{ Gender } & Male & 212 & 50.0 \\
\hline & Female & 212 & 50.0 \\
\hline \multirow{5}{*}{$\begin{array}{l}\text { Age of participants in } \\
\text { years }\end{array}$} & 25 years and below & 2 & 0.5 \\
\hline & $26-35$ years & 34 & 8.0 \\
\hline & $36-45$ years & 194 & 45.8 \\
\hline & $46-55$ years & 160 & 37.7 \\
\hline & 56 years and above & 34 & 8.0 \\
\hline \multirow[t]{4}{*}{ Marital status } & Single & 172 & 40.6 \\
\hline & Married & 208 & 49.0 \\
\hline & Divorced & 24 & 5.7 \\
\hline & Widowed & 20 & 4.7 \\
\hline \multirow{3}{*}{$\begin{array}{l}\text { Highest qualification } \\
\text { obtained }\end{array}$} & Diploma & 4 & 0.9 \\
\hline & Undergraduate degree & 68 & 16.0 \\
\hline & Postgraduate degree & 352 & 83.0 \\
\hline \multirow[t]{2}{*}{ Organisation } & Merged institution & 284 & 67.0 \\
\hline & Non-merged institution & 140 & 33.0 \\
\hline \multirow{4}{*}{$\begin{array}{l}\text { Position occupied in } \\
\text { the organisation }\end{array}$} & Junior lecturer & 103 & 24.3 \\
\hline & Senior lecturer & 259 & 61.1 \\
\hline & Professor & 43 & 10.1 \\
\hline & Part time lecturer & 19 & 4.5 \\
\hline \multirow{4}{*}{$\begin{array}{l}\text { Working experience } \\
\text { in the organisation }\end{array}$} & $<1$ year & 20 & 4.7 \\
\hline & $1-5$ years & 50 & 11.8 \\
\hline & $6-10$ years & 86 & 20.3 \\
\hline & 10 years and above & 268 & 63.2 \\
\hline
\end{tabular}

five different groups of nursing home samples (Siegrist \& Peter, 1996). In the South African context, an alpha of 0.50 was found among administrative personnel (Mxenge, Dywili, \& Bazana, 2014). Items that formed part of the scale include the following: 'I have constant pressure due to a heavy workload' and 'I receive the respect I deserve from my superiors'.

Uncertainty regarding future job security was measured with an adapted 10-item questionnaire, which asked the respondents to indicate their degree of certainty on whether or not they will have a job in the organisation after the merger (for the merging institution) or 'two years from now' (in the case of the non-merging institution). The whole questionnaire was measured on a five-point rating scale ranging from 'strongly disagree' (1) to 'strongly agree' (5).

\section{Data processing and analysis}

A statistical computer package, Statistics Package for Social Sciences (SPSS) version 25, was used to analyse data. Descriptive statistics were used to describe the sample profile. Several inferential statistical techniques were conducted to analyse data in this study. Firstly, an item analysis was performed to inspect the internal consistency of variables under investigation. Secondly, to determine the dimensionality of the scales, exploratory factor analysis was conducted. Thirdly, confirmatory factor analysis was conducted to determine the goodness of fit for the overall measurement model. Fourthly, independent-sample $t$-tests were used to compare the mean scores of the two independent groups from the two institutions ( $\mathrm{H} 1$ and $\mathrm{H} 2)$. Correlations were conducted to check the relationship of variables (H3 and $\mathrm{H} 4$ ). Finally, to test the degree to which uncertainty moderates the relationship between job satisfaction and occupational stress, moderated hierarchical multiple regression analysis was conducted (H5).

Reliability analysis: To check the reliability of the instruments and identify items that were not internally consistent with the other items in the instruments, an item analysis was conducted. Following the recommendations of Pallant (2016), items correlating below 0.30 with the total score were considered as poor items and were thus excluded from further analysis. The job satisfaction instrument contained two subscales, namely the hygiene factors subscale and the motivator factor subscale, which obtained an alpha of 0.756 after removing one poor item. The uncertainty scale found an alpha of 0.77 after removing four poor items. The Effort-Reward Imbalance scale, used to measure occupational stress, obtained a satisfactory internal consistency alpha coefficient of 0.78 after removing six poor items. This is shown in Table 2.

TABLE 2: Reliability statistics.

\begin{tabular}{lcc}
\hline Scale & Cronbach's alpha & Number of items \\
\hline Job satisfaction scale & 0.756 & 9 \\
Uncertainty scale & 0.770 & 6 \\
Occupational stress scale & 0.780 & 10 \\
\hline
\end{tabular}


Exploratory factor analysis: Principal component analysis using the varimax rotation method was used. The job satisfaction scale obtained an acceptable Kaiser-MeyerOlkin measure of sampling adequacy value of 0.716 and the Bartlett's Test of Sphericity test statistic value was 450.334 $(d f=21 ; p=0.000)$. Two factors that explained approximately $52 \%$ of variance were produced. However, three items were also removed due to cross-loading and the retained items are in Table 3. The occupational stress scale also obtained an acceptable Kaiser-Meyer-Olkin measure of sampling adequacy value of 0.832 and the Bartlett's Test of Sphericity test statistic value was $1055.199(d f=6 ; p=0.000)$.

One factor was obtained, and it explained $77 \%$ of the variance. One poor item was removed, and the retained items are presented in Table 3. Exploratory factor analysis was also conducted on the uncertainty scale and a good KaiserMeyer-Olkin measure of sampling adequacy value of 0.718 was found. The Bartlett's Test of Sphericity test statistic value was $471.534(d f=3 ; p=0.000)$. The scale was found to be unidimensional after removing two poor items. All retained items are presented in Table 3.

Dimensional analysis of job satisfaction: Principal component analysis was carried out on the nine items of the job satisfaction scale. The scale got an acceptable KaiserMeyer-Olkin measure of sampling adequacy value of 0.782 . The Bartlett's Test of Sphericity test was also significant at $568.385(d f=28 ; p=0.00)$. As expected, two components with eigenvalues larger than 1 were extracted. The two-factor solution explained a total of $51 \%$ variance, with component 1 contributing $31 \%$ and component 2 contributing $16 \%$. Oblimin rotation was performed and the rotated solution revealed a simple structure, with both components showing strong loadings. However, one item was removed from further analysis due to cross-loading. The retained items are shown in Table 3.

Dimensional analysis of the occupational stress scale: Principal component analysis, using the varimax rotation method, was also carried out on the retained 10 items of the occupational stress questionnaire. The scale obtained an

TABLE 3: Job satisfaction scale.

\begin{tabular}{|c|c|c|c|}
\hline \multirow[t]{2}{*}{ Item } & \multicolumn{2}{|c|}{ Component } & \multirow{2}{*}{$\begin{array}{c}\text { Total } \\
\text { variance } \\
\text { (50.226) }\end{array}$} \\
\hline & Factor 1 & Factor 2 & \\
\hline Eigenvalue & 2.77 & 1.248 & - \\
\hline Percentage of variance & 34.624 & 15.602 & - \\
\hline Working conditions & 0.748 & - & - \\
\hline $\begin{array}{l}\text { Opportunities to achieve something you } \\
\text { consider worthwhile }\end{array}$ & 0.598 & - & - \\
\hline Relationship with colleagues & - & 0.813 & - \\
\hline Company policy & 0.688 & - & - \\
\hline Work itself & - & 0.849 & - \\
\hline Relatioship with the immediate supervisor & - & 0.563 & - \\
\hline $\begin{array}{l}\text { The opportunities available for getting } \\
\text { ahead, for being promoted }\end{array}$ & 0.615 & - & - \\
\hline $\begin{array}{l}\text { The amount of money you receive as } \\
\text { compensation for the work you do }\end{array}$ & 0.615 & - & - \\
\hline
\end{tabular}

acceptable Kaiser-Meyer-Olkin measure of sampling adequacy value of 0.849 . The Bartlett's Test of Sphericity statistic was also significant at $1225.463(d f=10 ; p=0.00)$. One component with an eigenvalue greater than 1 was extracted. This single component explained $69 \%$ of the variance and all the items loaded strongly on the component. Four items were removed due to poor loading. The retained items are shown in Table 4.

Uncertainty questionnaire: Principal component analysis, using the varimax rotation method, was also carried out on the retained five items of the uncertainty questionnaire. The scale received an acceptable Kaiser-Meyer-Olkin measure of sampling adequacy value of 0.771 . The Bartlett's Test of Sphericity test statistic, which tests the overall significance of all the correlations within the correlation matrix, was also significant at $591.597(d f=6 ; p=0.00)$. One component with an eigenvalue above 1 was extracted and it explained $64 \%$ of variance. However, two items were identified with poor loading and were removed from further analysis. Another round of principal component analysis was carried out on the four retained items and the items loaded strongly on one component. The retained items are shown in Table 4.

\section{Evaluating the measurement models}

Confirmatory factor analysis was carried out on all the scales utilised in the study to assess the goodness of fit of the measurement models using the AMOS software. The overall measurement fit was done in two rounds. Several fit indices were used to assess model fit. As shown in Table 5, in the first round of confirmatory factor analysis, the $p$-value was 0.000 and root mean square error of approximation index was 0.076. Therefore, the two values were acceptable (Hair, Black, Babin, \& Anderson, 2010). The goodness of fit index, the comparative fit index, the incremental fit index and TuckerLewis index also fulfil the good fit requirement of being

TABLE 4: Occupational stress and uncertainty scale.

\begin{tabular}{lcc}
\hline Item & Component & Total variance \\
\hline Occupational stress & - & 69.016 \\
Eigenvalue & 3.451 & - \\
Percentage of variance & 69.016 & - \\
I have constant time pressure due to a & 0.885 & - \\
heavy work load. & & - \\
I have many interruptions and disturbances & 0.676 & - \\
in my job. & 0.891 & - \\
I have a lot of responsibilities in my job. & 0.845 & - \\
I am often pressured to work overtime. & 0.838 & - \\
Over the past few years, my job has & & - \\
become more and more demanding. & - & - \\
Uncertainty & 2.549 & - \\
Eigenvalue & 63.724 & - \\
Percentage of variance & 0.658 & - \\
It makes me anxious that I might become & & - \\
unemployed. & & \\
I fear that I might get fired. & 0.876 & - \\
There is a possibility that I might lose my & 0.841 & \\
job in the near future. & & \\
I think that I might be dismissed in the & 0.801 & \\
near future. & & \\
\hline
\end{tabular}


TABLE 5: Structural model fit summary.

\begin{tabular}{lcc}
\hline Fit index & $\begin{array}{c}\text { First round } \\
\text { indices }\end{array}$ & $\begin{array}{c}\text { Second round } \\
\text { indices }\end{array}$ \\
\hline$p$ & 0.000 & 0.000 \\
Goodness of fit index & 0.93 & 0.95 \\
Adjusted goodness of fit index & 0.89 & 0.93 \\
Parsimony goodness fit index & 0.63 & 0.64 \\
Normed fit index & 0.89 & 0.93 \\
Relative fit index & 0.87 & 0.91 \\
Incremental fit index & 0.92 & 0.96 \\
Tucker-Lewis index & 0.90 & 0.95 \\
Comparative fit index & 0.92 & 0.96 \\
Root mean square error of approximation index & 0.08 & 0.06 \\
\hline
\end{tabular}

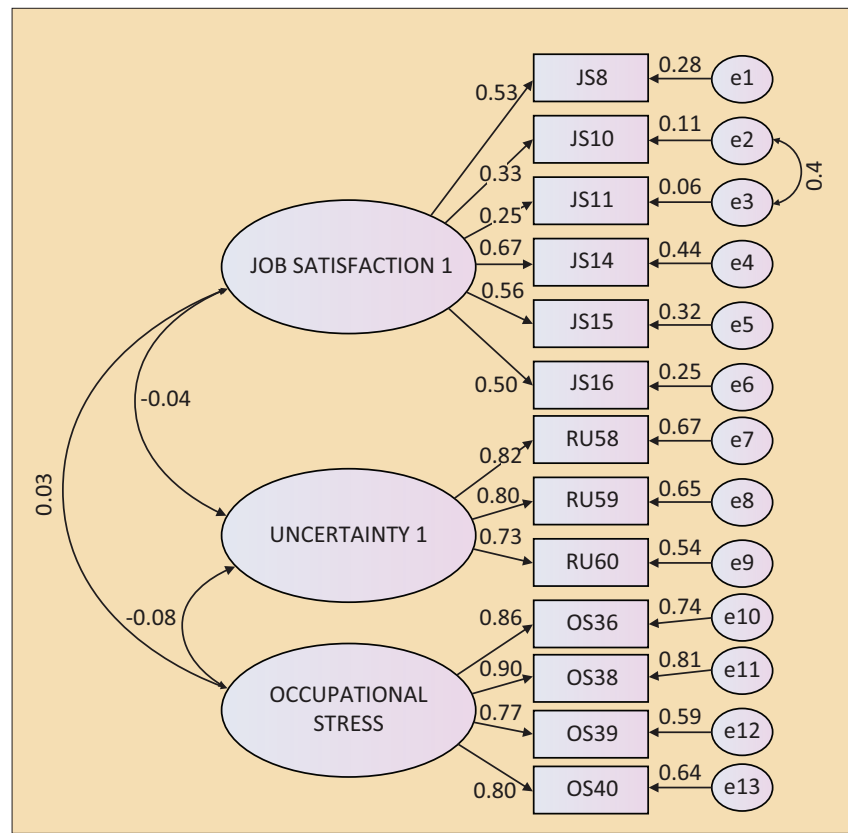

FIGURE 2: Structural measurement model.

larger than 0.90 , with values of $0.926,0.921,0.922$ and 0.901 (Hair et al., 2010).

However, the normed fit index was 0.89 and the relative fit index was 0.86 . These reflected a poor fit because they were below 0.90. Similarly, both the adjusted goodness of fit index and parsimony goodness fit index also missed the 0.90 level with values of 0.89 and 0.63 . These values indicated a poor fit. Therefore, results from the goodness of fit statistics indicated that the model had to be modified to obtain a better fit. Hence, item J10 (Interpersonal relationships: The social atmosphere of your workgroup, the kinds of feelings that exist between yourself and your fellow-workers) and J11 (Work itself: The actual work you perform) were co-varied as shown in Figure 2. After co-varying the two items, the second round of confirmatory factor analysis was conducted. Results showed that all the indices improved. Thus, data fit the measurement model as shown in Table 5, round two indices.

When collecting data, several ethical guidelines were followed. The participants were assured that the information provided would be confidential and their identities would remain anonymous. In addition, the study respondents were also informed about their right to participate or withdraw from the research at any time. Furthermore, all participants were informed that the information sought was solely for academic purposes and the improvement of the organisation.

\section{Ethical considerations}

Ethical clearance certificates were granted from each university's research office.

\section{Research results}

To compare whether there is a significant difference in the levels of employee job satisfaction in the two institutions, the independent-sample $t$-test was conducted $(\mathrm{H} 1)$. The results in Table 6 show that there is an insignificant difference between the levels of job satisfaction of employees in a nonmerged institution and those working in merged institutions as evidenced by a $p$-value greater than 0.05 . This suggests that employees in the two different institutions are similarly satisfied. Hence, we fail to reject the null hypothesis.

To test $\mathrm{H} 2$, which states that employees in a merging or merged institution experience higher occupational stress than those in a non-merged institution, an independentsample $t$-test was conducted. Significant differences $(t=$ 6.583; $d f=258 ; p<0.05)$ were reported in occupational stress levels for employees in a non-merged institution and those working for the merging institution. Mean differences show that employees in the merged institution show a higher level of occupational stress $(M=20.33 ; S D=5.134)$ than employees in the non-merged institution $(M=16.64 ; S D=5.571)$ as shown in Table 7 . Therefore, the null hypothesis was rejected and we concluded that employees in a merged institution have higher stress levels than those in a non-merged institution.

\section{Job satisfaction, occupational stresses, and uncertainty relationships}

Pearson product-moment correlation was used to check the relationship between job satisfaction and occupational stress, as well as the relationship between uncertainty and occupational stress. The results in Table 8 show that no relationship between job satisfaction and occupational stress was found $(p>0.05)$. A non-significant relationship between uncertainty and occupational stress was also found $(p>0.05)$. Therefore, null $\mathrm{H} 3$ and $\mathrm{H} 4$ were supported.

To check whether uncertainty moderates the relationship between job satisfaction and occupational stress, a two-stage moderated hierarchical multiple regression analysis was conducted (Baron \& Kenny, 1986). Job satisfaction was the independent variable, uncertainty was the moderator variable and occupational stress was the dependent variable. All variables were standardised before testing for moderating effect to reduce problems related to multicollinearity between the interaction term and the main effects $(\mathrm{Pu}, \mathrm{Hou}, \mathrm{Ma}, \&$ Sang, 2017). 
TABLE 6: Differences in employee's job satisfaction.

\begin{tabular}{llccccc}
\hline Variable & Institution & $\boldsymbol{N}$ & Mean & Standard deviation & $\boldsymbol{d f}$ & $\boldsymbol{T}$ \\
\hline \multirow{2}{*}{ Job satisfaction } & Non-merged & 284 & 31.25 & 5.457 & 422 & 1.318 \\
& Merged & 140 & 30.46 & 6.450 & - & - \\
\hline
\end{tabular}

TABLE 7: Difference between two groups of employees on occupational stress.

\begin{tabular}{|c|c|c|c|c|c|c|c|}
\hline Variable & Organisation & $N$ & Mean & Standard deviation & $d f$ & $T$ & $p$ \\
\hline \multirow[t]{2}{*}{ Occupational stress } & Merged institution & 284 & 20.33 & 5.134 & 258 & 6.583 & 0.000 \\
\hline & Non-merged institution & 140 & 16.64 & 5.571 & - & - & - \\
\hline
\end{tabular}

TABLE 8: Correlations of job satisfaction, occupational stresses and uncertainty $(N=424)$.

\begin{tabular}{|c|c|c|c|c|}
\hline Variable & Measurement & 1 & 2 & 3 \\
\hline \multirow[t]{2}{*}{ 1. Job satisfaction } & Pearson correlation & - & -0.002 & -0.041 \\
\hline & Significance (two-tailed) & - & 0.965 & 0.396 \\
\hline \multirow[t]{2}{*}{ 2. Occupational stress } & Pearson correlation & - & - & -0.091 \\
\hline & Significance (two-tailed) & - & - & 0.060 \\
\hline \multirow[t]{2}{*}{ 3. Uncertainty } & Pearson correlation & - & - & - \\
\hline & Significance (two-tailed) & - & - & - \\
\hline
\end{tabular}

*, significant at $95 \%$ confidence level.

TABLE 9: Uncertainty as a moderator of job satisfaction and occupational stress $(N=424)$.

\begin{tabular}{llcccccccc}
\hline Model & Variable & $\boldsymbol{R}^{\mathbf{2}}$ & Adjusted $\boldsymbol{R}^{\mathbf{2}}$ & $\boldsymbol{R}^{\mathbf{2}}$ change & $\boldsymbol{\beta}$ & $\boldsymbol{T}$ & $\boldsymbol{F}$ & $\boldsymbol{d}$ & \multicolumn{1}{c}{ Significance } \\
\hline 1 & JS, Uncertainty & 0.008 & 0.004 & 0.008 & - & 0.781 & 2.421 & 0.060 \\
2 & JS, Uncertainty, JS*Uncertainty & 0.021 & 0.014 & 0.013 & -0.112 & -2.318 & 2.991 \\
\hline
\end{tabular}

Note: Independent variable = job satisfaction; Moderator variable = Uncertainty; Dependent variable = occupational stress.

JS, job satisfaction.

$*, p<0.05$

In the first model, two variables were included, namely job satisfaction and uncertainty. The results show that these variables accounted for a non-significant amount of variance in occupational stress: $R^{2}=0.008, F(1.781)=2.421, p>0.05$ (Hox, Moerbeek, \& Van de Schoot, 2017). The interaction between job satisfaction and uncertainty accounted for a significant proportion of the variance in occupational stress: $R^{2}=-0.021, R^{2}$ change $\left(\Delta R^{2}\right)=0.031, F(2.991)=-3.420$, $\beta=-0.112, t=2.318, p<0.05$. Therefore, the results show a complete moderation. This suggests that uncertainty moderates the relationship between job satisfaction and occupational stress. Therefore, null $\mathrm{H} 5$ is rejected as shown in Table 9.

\section{Discussion}

No significant differences in the job satisfaction levels of employees working at the non-merged institution and those working at the merging institution were found. Hence, $\mathrm{H} 1$ is not supported. Contrary to these results, several studies found that a merger or even the announcement of one affects employees job satisfaction in a negative way (ArmstrongStassen, Mantler, \& Horsburgh, 2001; Burke, 2017; Martin \& Roodt, 2008).

Literature on mergers in South African institutions of higher learning also reported a significant difference in job satisfaction between employees affected by the merger and those not affected (Reddy, 2007). Another study by Viljoen and Rothmann (2009), on the impact of mergers on job satisfaction among academics in the United Kingdom, revealed that less than half of the British academics were satisfied with their jobs after a merger, while academics in other institutions not affected by a merger had high levels of job satisfaction.

It is rather surprising that the results of the present study are inconsistent with existing literature. Although unexpected, a possible explanation of this inconsistency could be the fact that the merging process of the studied institutions extended over a long period and is still ongoing. Hence, employees are no longer directly affected by the merger process. It is also imperative to note that both institutions that participated in this study are historically black rural institutions with virtually similar organisational cultures. Hence, the levels of job satisfaction between the institutions are almost the same regardless of merger status.

Significant differences were reported in occupational stress levels for employees working for the non-merged institution and those working for the merging institution. Mean differences show that employees at the merged institution have higher levels of occupational stress than those at the non-merged institution. Therefore, $\mathrm{H} 2$ is supported and we conclude that employees in a merged institution have higher stress levels than those in an unmerged institution. The possible explanation for this result is that employee involvement and open communication during the merger process is usually low (Genkova \& Gehr, 2016).

A study conducted among academics by Slade et al. (2016) also reported a positive relationship between a merger and employee stress. Other studies also revealed that organisational transformation through a merger will result in 
high employee occupational stress (Al-Hummadi, 2013; Armstrong-Stassen, Mantler, \& Horsburgh, 2001; Sharma, 2015; Zagelmeyer et al., 2018). Therefore, any organisation needs to manage a merger situation properly to minimise its possible emotional effects on employees.

In testing $\mathrm{H} 3$, which investigated the relationship between job satisfaction and occupational stress, an insignificant relationship was found. The results show that the two variables are not related. These findings are confirmed by Faragher et al. (2013) who also found an insignificant relationship between job satisfaction and occupational stress. In contrast, Burke (2017) and Yousef (2002) revealed that a negative relationship exists between job satisfaction and occupational stress.

No relationship was found between uncertainty and occupational stress (H4). This shows that uncertainty does not correlate with occupational stress, which was not expected. The observed results are in contrast with previous studies that found that a relationship exists between uncertainty and occupational stress (Cooper, 2018; Vander Elst et al., 2018; Warr, 2011). Thus, both H3 and H4 are not supported by the results.

This is probably because the merger has not been fully completed at the institution that was affected by the merger. From the findings, one can argue that organisations, through their human resource management departments, should provide an environment that will improve the satisfaction of employees, to minimise the effects of stress on both individuals and the organisation at large.

In testing $\mathrm{H} 5$, results further revealed that uncertainty moderates the relationship between job satisfaction and occupational stress. This indicates that the uncertainty levels of employees on whether their jobs are secure during an organisational change, influence the relationship between job satisfaction and occupational stress. In other words, the level of stress experienced by employees due to low job satisfaction during or because of a merger can be strengthened or weakened by the presence of job uncertainties. Employees will inevitably be more stressed when they are not certain that they will keep their jobs after the merger.

Literature has shown that studies on the relationship between job satisfaction and occupational stress, uncertainty and job satisfaction (Burke, 2017; Yousef, 2002), as well as between uncertainty and occupational stress are available (Barkhuizen \& Rothman, 2008; Warr, 2011). However, no studies were done on the moderating role of uncertainty on the relationship between job satisfaction and occupational stress in the South African higher education sector. Therefore, a study of this nature is necessary to assist managers or organisational change decision-makers in organisations to focus on job satisfaction and stress-related issues that might affect employees.

They should also be aware of other organisational factors such as uncertainty that might affect employees.

\section{Recommendations}

Based on the findings discussed above, it is recommended that future research should be conducted on the same constructs but focusing on more than two institutions of higher learning. It is also recommended that the management of higher learning institutions and other organisations should monitor the behaviours and attitudes of employees during and after the organisational change. Future studies on similar variables may also be conducted using a mixedmethod research approach. This will give more insight into the stress levels of employees in non-merged and merged institutions.

\section{Conclusion}

Considering that there are many changes taking place in higher education in several nations, it is important to investigate the level of job satisfaction and occupational stress of employees. The purpose of the study was to compare the levels of job satisfaction and occupational stress of employees in two institutions, as well as to examine the role of uncertainty in the relationship between job satisfaction and occupational stress. No differences in the level of job satisfaction were found between employees in a merged institution and those in a non-merged institution. However, significant differences in the levels of occupational stress were found. No relationship between job satisfaction and occupational stress and between uncertainty and occupational stress was found. Therefore, the study concludes that job satisfaction does not correlate with occupational stress, and uncertainty and occupational stress do not correlate either. It also concludes that uncertainty influences the relationship between job satisfaction and occupational stress. The researchers finally conclude that the study contributes to the literature on job satisfaction, and occupational stress and uncertainty influence the relationship between job satisfaction and occupational stress.

\section{Acknowledgements}

The authors declare that no funding or personal relationships may have inappropriately influenced them in writing this article.

\section{Competing interests}

No competing interests in writing this article.

\section{Authors' contributions}

H.N. contributed by writing this article and sourcing data from his $\mathrm{PhD}$ thesis, while T.Q.M. supervised and added his expertise in the work.

\section{Funding information}

This research received no specific grant from any funding agency in the public, commercial, or not-for-profit sectors. 


\section{Data availability statement}

Data sharing is not applicable to this article as no new data were created or analysed in this study.

\section{Disclaimer}

The views expressed in the submitted article are our own and not an official position of the institution or funder.

\section{References}

Al-Hummadi, B.A. (2013). Leadership, employee satisfaction and turnover in the UAE public sector (Unpublished doctoral thesis). Dubai: The British University.

Armstrong-Stassen, M., Mantler, J., \& Horsburgh, M.C. (2001). The impact of hospital amalgamation on the job attitudes of nurses. Canadian Journal of Administrative Sciences, 18(3), 149-162. https://doi.org/10.1111/j.1936-4490. 2001.tb00252.x

Arnolds, C.A., Lillah, R., \& Stofile, R.N. (2013). Assessing the outcomes of the higher education mergers in South Africa: Implications for strategic management. Acta Commercii, 13(1), 1-11. https://doi.org/10.4102/ac.v13i1.175

Bakker, A.B., Demerouti, E., \& Sanz-Vergel, A.I. (2014). Burnout and work engagement: The JD-R approach. Annual Review of Organizational Psychology and Organizational Behaviour, 1(1), 389-411. https://doi.org/10.1146/annurevorgpsych-031413-091235

Barkhuizen, N., \& Rothmann, S. (2008). Occupational stress of academic staff in South African higher education institutions. South African Journal of Psychology, 38(2), 321-336. https://doi.org/10.1177/008124630803800205

Baron, R.M., \& Kenny, D.A. (1986). The moderator-mediator variable distinction in social psychological research: Conceptual, strategic, and statistical considerations. Journal of Personality and Social Psychology, 51(6), 1173. https://doi. org/10.1037/0022-3514.51.6.1173

Bauer, F., \& Matzler, K. (2014). Antecedents of M\&A success: The role of strategic complementarity, cultural fit, and degree and speed of integration. Strategic Management Journal, 35(2), 269-291. https://doi.org/10.1002/smj.2091

Boyd, C.M., Tuckey, M.R., \& Winefield, A.H. (2014). Perceived effects of organizational downsizing and staff cut on the stress experience: The role of resources. Stress and Health, 30(1), 53-64. https://doi.org/10.1002/smi.2495

Burke, W.W. (2017). Organization change: Theory and practice. London: Sage Publications.

Carleton, J. R., \& Lineberry, C. (2004). Achieving post-merger success: A stakeholder's guide to cultural due diligence, assessment, and integration. New Jersey, NY: John Wiley \& Sons.

Cartwright, S., \& Cooper, C.L. (2014). Mergers and acquisitions: The human factor. Oxford: Butterworth-Heinemann.

Coffey, J., Garrow, V., \& Holbeche, L. (2012). Reaping the benefits of mergers and acquisitions: In search of the golden fleece. Oxford: Butterworth Heinemann.

Cooper, C.L. (Ed.). (2018). Managerial, occupational and organizational stress research. New York, NY: Routledge.

Creswell, J.W., \& Creswell, J.D. (2017). Research design: Qualitative, quantitative, and mixed methods approach. London: Sage Publications.

Faragher, E.B., Cass, M., \& Cooper, C.L. (2013). The relationship between job satisfaction and health: A meta-analysis. In From stress to wellbeing (vol. 1, pp. 254-271). London: Palgrave, Macmillan.

Genkova, P., \& Gehr, C. (2016). Is communication always helpful? The influence of organizational communication on feelings of uncertainty and commitment of employees during change management processes. International Journal of Academic Research in Business and Social Sciences, 6(1), 55-66. https://doi. org/10.6007/IJARBSS/v6-i1/1976
Graebner, M.E., Heimeriks, K.H., Huy, Q.N., \& Vaara, E. (2017). The process of postmerger integration: A review and agenda for future research. Academy of merger integration: A review and agenda for future research. Academy

Hair Jr, J.F., Black, W.C., Babin, B.J., Anderson, R.E., \& Tatham, R.L. (2010). SEM: An introduction. Multivariate data analysis: A global perspective, 5(6), 629-686.

Halpern, G. (1966). Relative contributions of motivator and hygiene factors to overall job satisfaction. Journal of Applied Psychology, 50(3), 198-200. https://doi. org $/ 10.1037 / \mathrm{h} 002342$

Hox, J.J., Moerbeek, M., \& Van de Schoot, R. (2017). Multilevel analysis: Techniques and applications (3rd edn.). New York, NY: Routledge.

Khamisa, N., Oldenburg, B., Peltzer, K., \& llic, D. (2015). Work-related stress, burnout, job satisfaction and general health of nurses. International Journal of Environmental Research and Public Health, 12(1), 652-666. https://doi. org/10.3390/ijerph120100652

Khan, Z., Soundararajan, V., Wood, G., \& Ahammad, M.F. (2017). Employee emotional resilience during post-merger integration across national boundaries: Rewards and the mediating role of fairness norms. Journal of World Business, 55(2), 1-11. and the mediating role of fairness norms. Jour
https://doi.org/10.1016/j.jwb.2017.06.009

Lee, C., Huang, G.H., \& Ashford, S.J. (2018). Job insecurity and the changing workplace: Recent developments and future trends in job insecurity research. Annual Review
of Organizational Psychology and Organizational Behavior, 5, 335-359. https:// of Organizational Psychology and Organizational B
doi.org/10.1146/annurev-orgpsych-032117-104651

Martin, A., \& Roodt, G. (2008). Perceptions of organisational commitment, job satisfaction and turnover intentions in a post-merger South African tertiary institution. SA Journal of Industrial Psychology, 34(1), 23-31. https://doi. org/10.4102/sajip.v34i1.415

Moran, P., \& Panasian, C. (2005). The human side of mergers and acquisitions: A look at the evidence. Lubbock, TX: Texas Technical University.

Mxenge, S.V., Dywili, M., \& Bazana, S. (2014). Organisational stress and employees' intention to quit amongst administrative personnel at the University of Fort Hare, Eastern Cape, South Africa. International Journal of Research in Social Sciences, 4(5), 207-227.

Pallant, J. (2016). SPSS survival manual: A step by step guide to data analysis using SPSS (6th edn.). London: McGraw-Hill.

Pu, J., Hou, H., Ma, R., \& Sang, J. (2017). The effect of psychological capital between work-family conflict and job burnout in Chinese university teachers: Testing for mediation and moderation. Journal of Health Psychology, 22(14), 1799-1807. https://doi.org/10.1177/1359105316636950

Reddy, T. (2007). Staff perceptions of the merger between two South African regional technikons. South African Journal of Higher Education, 21(3), 485-502. https:// technikons. South African Journal of
doi.org/10.4314/sajhe.v21i3.25719

Siegrist, J., \& Peter, R. (1996). Threat to occupational status control and cardiovascular risk. Israel Journal of Medical Sciences, 32(3-4), 179-184.

Slade, C.P., Ribando, S.J., \& Fortner, C.K. (2016). Faculty research following a merger: A job stress and social identity theory perspective. Scientometrics, 107(1), 71-89. https://doi.org/10.1007/s11192-016-1881-x

Sharma, L. (2015). Stress on employees amidst mergers of firms (an experience of the corporate sector). International Journal, 3(1), 368-370.

Van der Westhuizen, P.C. (2001). Effective educational management. Pretoria: HAUM.

Vander Elst, T., Notelaers, G., \& Skogstad, A. (2018). The reciprocal relationship between job insecurity and depressive symptoms: A latent transition analysis. Journal of Organizational Behaviour, 39(9), 1197-1218. https://doi.org/10.1002/job.2250

Viljoen, J.P., \& Rothmann, S. (2009). Occupational stress, ill-health and organisational commitment of employees at a university of technology. South African Journal of Industrial Psychology, 35(1), 67-77. https://doi.org/10.4102/sajip.v35i1.730

Warr, P. (2011). Work, happiness, and unhappiness. Sheffield: Psychology Press.

Yousef, D.A. (2002). Job satisfaction as a mediator of the relationship between role stressors and organizational commitment. Journal of Managerial Psychology 17(4), 250-266. https://doi.org/10.1108/02683940210428074

Zagelmeyer, S., Sinkovics, R.R., Sinkovics, N., \& Kusstatscher, V. (2018). Exploring the link between management communication and emotions in mergers and acquisitions. Canadian Journal of Administrative Sciences, 35(1), 93-106. https:// doi.org/10.1002/cjas.1382 